\title{
Anatomicopathological Evidence of the Beginning of Atherosclerosis in Infancy and Adolescence
}

\author{
Lucimar Aparecida Françoso, Veronica Coates
}

São Paulo, SP - Brazil

Atherosclerotic disease arises as a consequence of the formation of fatty plaques in the arterial wall that, in the advanced stage, can obstruct the lumen of a vessel, resulting in acute ischemic syndromes, which include coronary artery, cerebrovascular, and peripheral vascular disease.

Coronary artery disease is presently one of the major causes of death in developed countries throughout the world, and the main cause of death in the United States where it is responsible for more that 500,000 deaths per year ${ }^{1}$.

Considerable evidence suggests that the process of atherosclerotic plaque formation start in infancy, progressing slowly until adult life when, after a long asymptomatic period, clinical manifestations of the disease can be verified.

Our objective is the presentation of the results of a literature search of studies documenting, on the basis of child and adolescent necropsies, the beginning of atherosclerotic disease in the pediatric age group.

Early hypotheses about mechanisms involved in atherogenesis arose in the middle of the nineteenth century. Currently, it is accepted that the pathogenesis of atherosclerosis represents the answer to aggression against the arterial endothelium, as initially proposed in $1856^{2,3}$. Endothelial injury constitutes the initial event of the process of formation of the atherosclerotic plaque, and atherogenesis may be considered a protective inflammatory response to endothelial aggression ${ }^{3}$.

As a result of endothelial injury, blood monocytes are chemotactically attracted to the arterial wall, entering the subendothelial space where, by means of complex processing, they are changed into macrophages. These cells incorporate large quantities of oxidized LDL (low-density lipoproteins) particles, transforming them into foam cells, which constitute the first chemically and microscopically detectable lesion by lipid deposits in the artery intima. Subse-

Faculdade de Ciências Médicas da Santa Casa de São Paulo

Mailing address: Lucimar Aparecida Françoso - Rua Teodoro Sampaio, 363/319

05405-000 - São Paulo, SP - Brazil - E-mail: lucimarfrancoso@uol.com.br quently, monocytes continue to migrate to the intima; smooth muscle cells also start to migrate from the middle layer; also to accumulate lipid droplets, acquiring the appearance of foam cells. Following side-by-side localization on the intima's surface, these cells become macroscopically visible as yellowish fatty streaks ${ }^{3-6}$.

As the process evolves, not all modified LDL particles are taken up by macrophages. Some remain partly deposited in the extracellular matrix as groups of fat droplets ${ }^{6,7}$. This leads to a dense accumulation of lipids in the extracellular space, constituting the so-called lipid nuclei formed by the increase and confluence of small groups of extracellular lipids. This lesion, called an atheroma, leads to intensive disorganization of the intima and thickening of the arterial wall that can be seen undergoing fissures, with the naked eye undergoing ${ }^{8}$.

As the process evolves, formation of fibrous connective tissue sets in. When associated with a lipid nucleus, it constitutes a fibroatheroma, containing a lipid nucleus, a fibrous plaque covering and giving rise to a hematoma, hemorrhage, and thrombosis. This situation constitutes the major cause of morbidity and mortality secondary to atherosclerosis ${ }^{8}$.

Stary et al ${ }^{8}$ classified these lesions according to histological types as shown on Figure 1.

Foam cells and fatty streaks may arise during the first decade of life, intermediary lesions and atheroma arise during the third decade, and fibroatheromas and more complicated lesions start during the 4 th decade.

The first publications on atherosclerosis appeared at the beginning of the nineteenth century. Scarpa described the presence of fatty material and degeneration of the arterial wall of the coronaries of adult anginous individuals. From then on, several studies demonstrated that atheromatous plaques are associated with excess fat and cholesterol in the blood ${ }^{9,10}$. Publications reporting on early formation of the atherosclerotic plaque in children and adolescents appeared at the same time.

In 1908, Fremont-Smith ${ }^{11}$ published a literature review on atherosclerosis in youngsters, reporting that various 


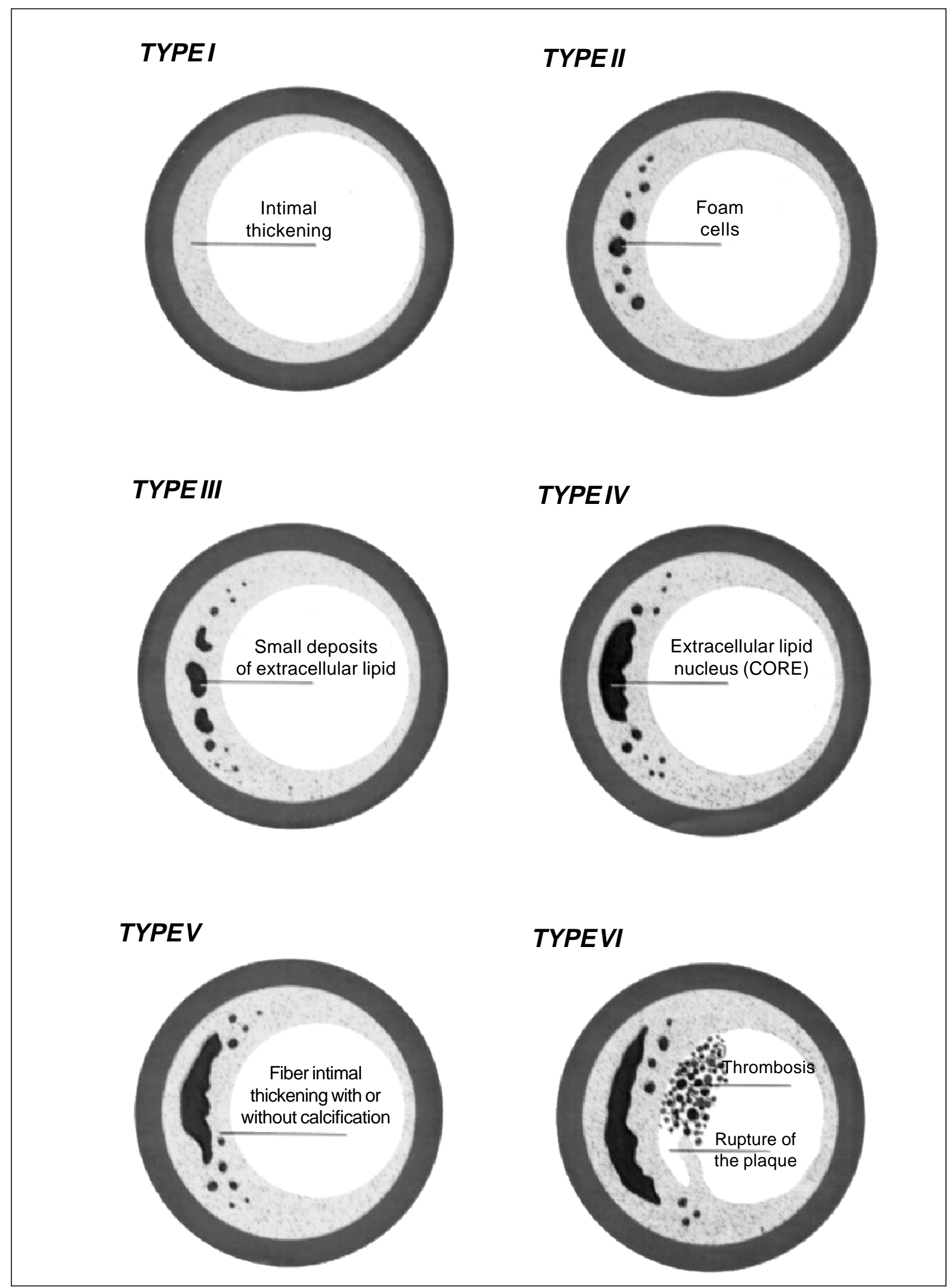

Fig. 1 - Histological types of atheromatous plaques, according to Stary. Source: Modified from Stary et al., Circulation 1995; 92:13461-62. Extracted with permission from Ihara et al. In: Martinez \& Lourenço. Avaliação e condutas nos riscos trombo e aterogênico - São Paulo: Art Plus, 1996:47. 
authors had found the disease in autopsies of adolescents and young adults who had died from acute infectious processes, thus establishing a relationship between acute infection and arterial disease.

In 1930, Zeek $^{9}$ in a review of the literature on juvenile atherosclerosis observed that the first mention of this condition in children was that of Hodgson in 1815. The author selected 98 well-defined cases of atherosclerosis in subjects up to 20 years of age and concluded that atherosclerosis can occur at any age level from birth onwards, without differences due to sex.

Enos et al ${ }^{12}$ found grossly visible atherosclerosis in the coronary arteries of $77.3 \%$ of 300 American soldiers aged between 18 and 48 years, killed in the Korean War. The study called attention to atherosclerosis in young people.

Holman et al ${ }^{13}$ in necropsy studies on 526 individuals aged from 1 to 40 years noted the appearance of fatty streaks from the first year of life on, and that the percentage of the arterial surface involved increased slowly until the age of 8 years, but afterwards progressed more rapidly. Fibrous plaques appeared in the second decade of life, increased until the third so that after the age of $30,90 \%$ of the aortas had showed some degree of fibrous plaques. The conversion of streaks to fibrous plaques took approximately 15 years, and at 40 years about $20 \%$ of the area covered by the streaks had changed into fibrous plaques. The Caucasian race was most affected, as was the abdominal segment of the aorta $^{13}$.

Strong and McGill ${ }^{14}$ dissected coronary arteries during 548 necropsies of patients from 1 to 69 years of age, observing that gross lesions were rare during the first decade of life, but rapidly increased over the following decades, becoming nearly universal in subjects over 40 years of age. In Caucasian men, coronary lesions developed more rapidly after the 4th decade of life; in blacks and women, development began from the 5th and 6th decades on. Patients who died from ischemic heart disease had more extensive lesions than those dying from other causes, strengthening the hypothesis that atherosclerosis is the most significant cardiac population risk and that lesions develop at least 20 years prior to the beginning of clinical manifestations ${ }^{14}$.

The International Atherosclerosis Project, an extensive study about the geographic distribution of this disease involving 14 nations including the USA, Chile, Colombia, Puerto Rico, Costa Rica, Brazil, Guatemala, and South Africa, in 1968 published results of necropsies performed in 4,737 individuals of both sexes, aged between 10 and 39 years. The sequence of fat deposition occurred in the following manner in these subjects. The aorta was the first structure involved starting at infancy with the formation of fatty streaks, and peaking at puberty. In the coronaries, fatty streaks began at puberty, increasing significantly in the third decade of life, showing inclusively an evolution towards fibrous plaques. The carotids started to become involved at the same age range as the aorta; cerebral arteries were affected simultaneously with the coronaries ${ }^{15-17}$.

Kagan ${ }^{18}$ and Vanecek ${ }^{19}$ published the results of a study by the World Health Organization in 5 European towns. Fatty streaks and fibrous plaques were found in the coronaries of individuals between 10 and 14 years of age; coronary stenosis was found in men over 20 years of age and in women 10 years later, frequencies increased with aging.

Studies by Hirvonen et al $^{20}$ in Finland demonstrated the existence of intimal thickening in coronary arteries in $53 \%$ of 75 healthy children including those under 5 years of age necropsied after death due to external causes.

Newman et al ${ }^{21}$ published the first results of the Bogalusa Heart Study, an important epidemiological research study performed in children, adolescents, and young adults. The study analyzed the presence of cardiovascular disease risk factors in children from birth to 26 years of age. The research correlated necropsy material with risk factors detected antemortem, observing that an important relationship existed between lipoprotein levels and arterial disease. This finding permitted the association between the presence of fibrous plaques in the coronaries and high levels of triglycerides and arterial pressure. The extent of fatty streaks was strongly correlated with high serum levels of total cholesterol and LDL and inversely-with HDL levels. The study concluded that risk factors are related to the development of atherosclerotic lesions starting at the most precocious stages of infancy.

Tanaka et al $^{22}$ in Japan, studying 2,856 patients dying between 1 month and 39 years of age, showed the presence of fatty streaks in the aortas of $29 \%$ of children less than 1 year old. Between 1 and 9 years, streaks were found in the coronaries of $3.1 \%$ of the cases, and in cerebral arteries of $1.9 \%$. Above 10 years of age, lesions increased in coronary and cerebral arteries, progressed with age. Fatty streaks evolved rapidly in the second decade of life, and fibrous plaques increased during the third. Antemortem risk factors like age, serum cholesterol, and blood pressure levels were positively correlated with the extent of aortic and coronary lesions. Cerebral artery lesions showed a significant correlation with arterial pressure levels only.

Stary ${ }^{23,24}$ evaluated atherosclerosis progression in infants' and young adults' coronaries by studying arteries during necroscopy of 691 individuals who died between the first day of life and 39 years of age. Foam cells, which regressed following the first year of life, were observed in the artery intima of $45 \%$ of children up to 8 months of life. They returned at puberty, so that between 10 and 14 years $61 \%$ had large amounts of foam cells and fatty streaks. Advanced lesions were found in respectively, 7\%, 14\%, 21\%, 33\%, $61 \%$, and $66 \%$ of individuals aged between 10 and 14,15 and 19, 20 and 24, 25 and 29, 30 and 34, and 35 to 39 years, being more prevalent in males.

Pesonen et $\mathrm{al}^{25}$ analyzed coronary artery narrowing in individuals between 1 to 16 years of life, observing a $17 \%$ narrowing of the left coronary during the first year of life, and of $34 \%$ narrowing between 12 and 15 years, being more pronounced in males. Subjects who had a higher degree of narrowing descended from grandparents coming from areas 
having a high mortality rate due to coronary artery disease; this suggested a hereditary predisposition.

Angelini et al ${ }^{26}$ observed intimal proliferation of $95.3 \%$ of the coronary segments of children between 1 and 5 years of age. Fibrous plaques were detected from 6 years of age onwards, $24 \%$ of the individuals between 16 and 20 years with 1 or more plaques. The most affected site was the proximal part of the anterior descending artery.

New results from the Bogalusa Heart Study ${ }^{27}$ were published following the analysis of aortas and coronaries of 150 necropsies of individuals aged between 6 and 30 years. The study reinforced the earlier conclusion that risk factors are correlated with the development of atherosclerosis and emphasized the need for cardiological prevention from the beginning of life.

Kaprio et al ${ }^{28}$ evaluated the relationship between death from arterial coronary disease of grandparents and thickening of the intima in 136 children. The relationship was positive for 77 children, being most frequent in those with narrowing of the coronary lumen.

The multicenter study Pathological Determinants of Atherosclerosis in Youth (PDAY) ${ }^{29}$ revealed that all aortas and about half of the right coronaries of 1,532 necropsies had atherosclerotic lesions in individuals aged between 15 and 19 years and that the extent of the lesions increased with age. The $50 \%$ prevalence of right coronary lesions in the younger group went up to $75 \%$ in the 30 - to 34-year-old group and was greater in men who had more extensive coronary involvement and a greater trend towards evolution to more serious forms of the lesions.

Cornhill et $\mathrm{al}^{30}$ in the PDAY study related the role of risk factors in the development and progress of arterial lesions in individuals between 15 and 34 years of age, indicating that aortic and right coronary atherosclerosis were positively associated with levels of LDL and VLDL, glucose intolerance, smoking, arterial hypertension, and obesity, and negatively associated with HDL levels. The authors suggested that a precocious modification of risk factors might benefit the retardation of the evolution of the disease.

Tracy et al $^{31}$ in a continuation of the Bogalusa Heart Study reinforced results obtained since the beginning of the research, by connecting the presence of aortic fatty streaks with antemortem serum levels of total cholesterol and LDL, and an inverse relationship with HDL. An association of right coronary lesions with high levels of total cholesterol, LDL, VLDL, and arterial hypertension was shown. New results showed that the presence of multiple concomitant risk factors aggravates atherosclerotic lesions of the aorta and coronaries, demonstrating a synergic effect on lesion evolution ${ }^{32}$.

Strong et $\mathrm{al}^{33}$ related new results of the PDAY study, totaling 2,876 individuals aged between 15 and 34 years dying from external causes, confirming earlier observations and concluding that the prevalence and extension of lesions increase rapidly over this age interval-and that atherosclerotic disease should be prevented starting in infancy and adolescence.

\section{Commentary}

As already mentioned, interest in atherosclerosis in infancy and adolescence arose in the beginning of the nineteenth century; from then on, several reports on the presence of arterial lesions in these age groups have appeared. Many necropsy studies have been published indicating the precocious beginning of atherosclerotic lesions in infancy. The Bogalusa Heart Study and the PDAY Study correlated the occurrence of such lesions with the presence of risk factors and raised the possibility that the latter could precociously be involved in the later development of coronary artery disease.

In view of what has been revealed in the literature, evidence that the initiation of atherosclerotic lesions begins in infancy is no longer arguable; neither is the occurrence of a correlation between these lesions and the presence of risk factors in this age group, despite the still small number of studies confirming this relationship.

In spite of this evidence, the literature still discusses the need for programs aimed at the tracking of serum lipid and lipoprotein concentrations in the pediatric age group. Such tracking aims at the precocious detection and intervention on possibly elevated levels of lipids, considering the physiological alterations that occur for example during adolescence.

Some authors are against the tracking of lipid levels in the pediatric age group, claiming difficulties in its performance, high cost, adverse effects of labeling a child as hypercholesterolemic, and lack of demonstrable benefits of decreasing lipid levels in infancy to prevent disease in the adult $^{34-42}$.

At the other extreme are authors who favor universal tracking of all children, regardless of the existence or nonexistence of risk factors, defending the idea that this type of tracking is more sensitive and could benefit children having high lipid levels ${ }^{43-46}$. The Bogalusa Heart Study recommends tracking of cardiovascular risk factors, including total cholesterol and, when indicated, lipoproteins, as well as arterial pressure, weight, height, diet, physical activity, and smoking of all children during or prior to pre-school examination ${ }^{47}$.

The National Cholesterol Education Program (NCEP) adopted an intermediary position, recommending the selective tracking of lipid levels of children above 2 years of age with a family history of hypercholesterolemia or precocious, that is prior to 55 years, cardiovascular disease, or of those whose family history cannot be obtained ${ }^{1}$.

The American Academy of Pediatrics adopted and maintains the recommendations established by the $\mathrm{NCEP}^{48}$. The Brazilian Society of Cardiology through the Second Brazilian Consensus on Dyslipidemias also recommends selective tracking of the lipid profile of children and adolescents of the 2- to 19-year age group based on their family history and the presence of other risk factors ${ }^{49}$. Values for reference are found in Table I.

Prevention is the main form of control of disease 


\begin{tabular}{|c|c|c|c|c|}
\hline \multirow[t]{2}{*}{ Lipids } & \multirow[t]{2}{*}{ Age } & \multicolumn{3}{|c|}{ Values (mg/dL) } \\
\hline & & Desired & Increased & Limiting \\
\hline CT & & $<170$ & $170-199$ & $\geq 200$ \\
\hline LDL-c & & $<110$ & $110-129$ & $\geq 130$ \\
\hline \multirow{2}{*}{ HDL-c } & $<10$ & $\geq 40$ & - & - \\
\hline & $10-19$ & $\geq 35$ & - & - \\
\hline \multirow[t]{2}{*}{ TG } & $<10$ & $\leq 100$ & - & $>100$ \\
\hline & $10-19$ & $\leq 130$ & - & $>130$ \\
\hline $\begin{array}{l}\text { Source: } \\
\text { on Disli }\end{array}$ & $\begin{array}{l}\text { lian So } \\
\text { nias, } 19\end{array}$ & of Card & Second $\mathrm{I}$ & Consensu \\
\hline
\end{tabular}

consequent to atherosclerosis, and little has been done in terms of its implementation, especially in pediatric practice. The pediatrician, in general the only professional who accompanies an individual from his birth onwards, can fulfill an important role in the promotion of cardiovascular health by not limiting his focus of attention to diseases of childhood, but approaching adult disease as having its origin in the pediatric age group ${ }^{50,51}$.

According to the recommendations of the American Academy of Pediatrics and the Brazilian Society of Cardiology, indiscriminate determination of the lipid profile in children and adolescents is not recommended. Nevertheless, tracking between 2 and 19 years of age should be performed in the following situations: presence of grandparents, parents, brothers, uncles, and first cousins with coronary, or cerebrovascular, or peripheral manifest arterial disease or a combination of these earlier than 55 years of age in men and earlier than 65 years in women, close relatives with total cholesterol levels $\geq 300 \mathrm{mg} / \mathrm{dL}$ or triglycerides $\geq 400 \mathrm{mg} / \mathrm{dL}$, presence of acute pancreatitis, xanthomatosis, obesity, or other risk factors for arterial coronary disease of the child or youngster.

Regrettably, not all pediatricians know about these recommendations and few include tracking and measures for the prevention of adult diseases in their daily practice.

Yet, the prevention of atherosclerosis is a responsibility of the pediatrician. He should identify and control cardiovascular risk factors present in infancy and adolescence by promoting cardiovascular health to his patients through the prevention or control, or both prevention and control of obesity, by encouraging regular physical exercise, by the detecting and controlling of arterial hypertension, encouraging healthy eating habits, discouraging -smoking by adolescents and, when indicated, tracking of lipid levels ${ }^{46,51}$.

Cardiology societies in collaboration with those of pediatrics could perhaps promote campaigns for the clarification and sensitization of pediatricians on how to prevent factors capable of impairing cardiovascular health in adult life, from infancy onwards. In addition, they could promote campaigns to improve the understanding of healthier ways of life by the public.

In conclusion, the process of the formation of atherosclerotic lesions begins in infancy, being detectable already during the first year of life. Risk factors favoring the development of atherosclerotic lesions are present during infancy; their prevention should also begin during this period.

\section{References}

1. National Cholesterol Education Program (NCEP). Highlights of the report of the Expert Panel on Blood Cholesterol Levels in Children and Adolescents. Pediatrics 1992; 89: 495-501.

2. Ihara SSM, Novazzi JP, FonsecaFAH, Pinto LESA, Martinez TLR. Lipoproteínas e aterogênese. In: Martinez TLR. Condutas Clínicas nas Dislipidemias. Belo Horizonte: Health; 1997: 55-70.

3. Ross R. The pathogenesis of atherosclerosis: a perspective for the 1990s. Nature 1993; 362: 801-9.

4. Ross R, Glomset JA. The pathogenesis of atherosclerosis. N Engl J Med 1976; 295: 369-80.

5. Fuster V, Badimon L, Badimon JJ, Chesebro JH. The pathogenesis of coronary artery disease and the acute coronary syndromes. NEngl J Med 1992; 326: 242-50.

6. Stary HC, Chandler AB, Glagov S, et al. A definition of initial, fatty streak and intermediate lesions of atherosclerosis: a report from the Committee on Vascular Lesions of the Council on Arteriosclerosis. Circulation 1994; 89: 2462-78.

7. Kovanen PT. Atheroma formation: defective control in the intimal round - trip of cholesterol. Eur Heart J 1990; 11(suppl E): 238-46.

8. Stary HC, Chandler AB, Dinsmore RE, et al. A definition of advanced types of atherosclerotic lesions and a histological classification of atherosclerosis: a report from the Committee on Vascular Lesions of the Council on Arteriosclerosis. Circulation 1995; 92: 1355-74.

9. Zeek P. Juvenile arteriosclerosis. Arch Pathol 1930; 10: 417-46.

10. Heald FP. The history of pediatric concern with atherosclerosis. In: Jacobson MS. Atherosclerosis Prevention: Identification and Treatment of the Child With High Cholesterol. New York: Harwood Academic Publishers, 1991: 9-14

11. Fremont-Smith F. Arteriosclerosis in the young. Am J Med Sci 1908; 135: 199-207.

12. Enos WF, Holmes RH, Beyer J. Coronary disease among united states soldiers killed in action in korea. JAMA 1953; 152: 1090-3.
13. Holman RL, McGill HC, Strong JP, Geer JC. The natural history of atherosclerosis: the early aortic lesions as seen in New Orleans in the middle of the $20^{\text {th }}$ century. Am J Pathol 1958; 34: 209-29.

14. Strong JP, McGill HC. The natural history of coronary atherosclerosis. Am J Pathol 1962; 40: 37-49.

15. McGill HC, Arias-Stella J, Carbonell LM, et al. General findings of the International Atherosclerosis Project. Lab Invest 1968; 18: 498-502.

16. McGill HC. Fatty streaks in the coronary arteries and aorta. Lab Invest 1968; 18:560-4

17. Strong JP, McGill HC. The pediatric aspects of atherosclerosis. J Atheroscler Res 1969; 9: 252-65.

18. Kagan AR. Aortic, coronary, and myocardial lesions in relation to various factors Bull World Health Organ 1976; 53: 605-14

19. Vanecek R. Atherosclerosis of the coronary arteries in five towns. Bull World Health Organ 1976; 53: 509-18.

20. Hirvonen J, Yla-Herttuala S, Laaksonen H, et al. Coronary intimal thickenings and lipids in finnish children who died violently. Acta Pediatr Scand Suppl 1985; 318: 221-4.

21. Newman III WP, Freedman DS, Voors AW, et al. Relation of serum lipoprotein levels and systolic blood pressure to early atherosclerosis: the Bogalusa Heart Study. N Engl J Med 1986; 314: 138-44.

22. Tanaka K, Masuda J, Imamura T, et al. A nation-wide study of atherosclerosis in infants, children and young adults in Japan. Atherosclerosis 1988; 72: 143-56.

23. Stary HC. Evolution and progression of atherosclerotic lesions in coronary arteries of children and young adults. Arteriosclerosis 1989; 9(suppl I): I 19-I 32.

24. Stary HC. The sequence of cell and matrix changes in atherosclerotic lesions of coronary arteries in the first forty years of life. Eur Heart J 1990; 11(suppl E): 3-19.

25. Pesonen E, Norio R, Hirvonen J, et al. Intimal thickening in the coronary arteries 
of infants and children as an indicator of risk factors for coronary heart disease. Eur Heart J 1990; 11(suppl E): 53-60.

26. Angelini A, Thiene G, Frescura C, Baroldi G. Coronary arterial wall and atherosclerosis in youth (1-20 years): a histologic study in a northern Italian population. Int J Cardiol 1990; 28: 361-70.

27. Berenson GS, Wattigney WA, Tracy RE, et al. Atherosclerosis of the aorta and coronary arteries and cardiovascular risk factors in persons aged 6 to 60 years and studied at necropsy (The Bogalusa Heart Study). Am J Cardiol 1992; 70: 851-8.

28. Kaprio J, Norio R, Pesonen E, Sarna S. Intimal thickening of the coronary arteries in infants in relation to family history of coronary artery disease. Circulation 1993; 87: 1960-8

29. The Pathobiological Determinants of the Atherosclerosis in Youth (PDAY) Research Group. Natural history of aortic and coronary atherosclerosis lesions in youth: findings from the PDAY Study. Arterioscler Thromb 1993; 13: 1291-8.

30. Cornhill JF, Herderick EE, Vince DG. The clinical morphology of human atherosclerotic lesions: lessons from the PDAY Study. Pathobiological determinants of atherosclerosis in youth. Wien Klin Wochenschr 1995; 107: 540-3.

31. Tracy RE, Newman WP, Wattigney WA, Berenson GS. Risk factors and atherosclerosis in youth: autopsy findings of The Bogalusa Heart Study. Am J Med Sci 1995; 310(suppl 1): S37-S41.

32. Berenson SG, Srinivasan SR, Bao W, Newman III WP, Tracy RE, Wattigney WA Association between multiple cardiovascular risk factors and atherosclerosis in children and young adults. N Engl J Med 1998; 338: 1650-6.

33. Strong JP, Malcom GT,McMahan CA, etal.Prevalence and extent of atherosclerosis in adolescents and young adults: implications for prevention from the Pathobiological Determinants of Atherosclerosis in Young Study. JAMA 1999; 281:727-35.

34. Toronto Working Group on Cholesterol Policy. Asymptomatic hypercholesterolemia: a clinical policy review. J Clin Epidemiol 1990; 43: 1028-121.

35. Feldman W. Routine cholesterol surveillance in childhood. Pediatrics 1990; 86:150-1.

36. Hulley SB,Newman TB, Grady D, GarberAM,BaronRB, BrownerWS. Should we be measuring blood cholesterol levels in young adults? JAMA 1993; 269: 1416-9.

37. Sox Jr HC. Screening for lipid disorders under health system reform. NEngl J Med 1993; 328: 1269-71
38. Newman TB, Garber AM, Holtzman NA, HulleY SB. Problems with the report of the expert panel on blood cholesterol levels in children and adolescents. Arch Pediatr Adolesc Med 1995; 149: 241-7.

39. Canadian Task Force on Periodic Health Examination. Periodic health examination, 1993 update: 2 . Lowering the blood total cholesterol level to prevent coronary heart disease. Can Med Assoc J 1993; 148: 521-38.

40. Newman TB, Browner WS, Hulley SB. The case against childhood cholesterol screening. JAMA 1990; 264: 3039-43.

41. Lauer RM, Clarke WR. Use of cholesterol measurements in childhood for the prediction of adult hypercholesterolemia: the Muscatine Study. JAMA 1990; 264 : 3034-8.

42. Newman TB, Garber AM. Rastreio do colesterol em crianças e adolescentes. Pediatrics (Ed. Brasil.) 2000; 4: 345- 7.

43. Garcia RE, Moodie DS. Routine cholesterol surveillance in childhood. Pediatrics 1989; 84: 751-5.

44. Wynder E. An American Health Foundation monograph: coronary artery disease prevention: cholesterol, a pediatric perpective. Prev Med 1989; 18: 323-409.

45. Franklin JrFA, Brown RF, Franklin CC. Screening, diagnosis, and manegement of dyslipoproteinemia in children. Endocrinol Metab Clin North Am 1990; 19: 399-449.

46. Strong WB. Cholesterol screening as a component of pediatric preventive cardiology: the office setting in hyperlipidemia in children. Ann N Y Acad Sci 1991; 623: 214-21.

47. Berenson GS, Srinivasan SR, WebberLS, et al. Cardiovascular risk in early life: the Bogalusa Heart Study. Current Concepts. Michigan: Upjohn Company; 1991.

48. American Academy of Pediatrics. Committee on Nutrition. Cholesterol in childhood. Pediatrics 1998; 101: 141-7.

49. Sociedade Brasileira de Cardiologia. Segundo Consenso Brasileiro sobre Dislipidemias - detecção, avaliação e tratamento. Arq Bras Cardiol 1996; 67: 113-28.

50. Jacobson MS. The pediatrician's role in atherosclerosis prevention. J Pediatr 1988; 112: 836-41

51. Bronfin DR, Urbina EM. The role of the pediatrician in the promotion of cardiovascular health. Am J Med Sci 1995; 310(suppl 1): S42-S47. 